\title{
Comparison between seismic and domestic risk in moderate seismic hazard prone region: the Grenoble City (France) test site
}

\author{
F. Dunand ${ }^{1}$ and P. Gueguen ${ }^{2}$ \\ ${ }^{1}$ GEOTER, Pôle Géoenvironnement, 2 rue Jean Monnet, 34830 Clapiers, France \\ ${ }^{2}$ ISTerre, Universite Joseph Fourier - Grenoble 1, CNRS, IFSTTAR, BP 53, 38041 Grenoble Cedex 9, France \\ Correspondence to: P. Gueguen (pgueg@obs.ujf-grenoble.fr)
}

Received: 26 April 2011 - Revised: 28 October 2011 - Accepted: 10 January 2012 - Published: 29 February 2012

\begin{abstract}
France has a moderate level of seismic activity, characterized by diffuse seismicity, sometimes experiencing earthquakes of a magnitude of more than 5 in the most active zones. In this seismicity context, Grenoble is a city of major economic and social importance. However, earthquakes being rare, public authorities and the decision makers are only vaguely committed to reducing seismic risk: return periods are long and local policy makers do not have much information available. Over the past $25 \mathrm{yr}$, a large number of studies have been conducted to improve our knowledge of seismic hazard in this region. One of the decision-making concerns of Grenoble's public authorities, as managers of a large number of public buildings, is to know not only the seismic-prone regions, the variability of seismic hazard due to site effects and the city's overall vulnerability, but also the level of seismic risk and exposure for the entire city, also compared to other natural or/and domestic hazards. Our seismic risk analysis uses a probabilistic approach for regional and local hazards and the vulnerability assessment of buildings. Its applicability to Grenoble offers the advantage of being based on knowledge acquired by previous projects conducted over the years. This paper aims to compare the level of seismic risk with that of other risks and to introduce the notion of risk acceptability in order to offer guidance in the management of seismic risk. This notion of acceptability, which is now part of seismic risk consideration for existing buildings in Switzerland, is relevant in moderately seismic-prone countries like France.
\end{abstract}

\section{Introduction}

In the summary of risk levels for different dangers proposed by Breysse (2009), two types of risk are identified: (1) voluntary risk, i.e. the risk taken voluntarily by a person in order to obtain a certain benefit (e.g. parachuting or helicopter flight). The level of acceptability may be high for this type of risk due to its voluntary nature. (2) involuntary risk, i.e. the risk suffered by the population or a company and not chosen freely (e.g. exposure to an earthquake or fire). For this type of risk, the level of acceptability is low, since it is often perceived as being inevitable. Public authorities responsible for public safety make rules to reduce the levels of both voluntary and involuntary risks. They rely on precise knowledge of the risk levels to enable the risk reduction schemes available (from an economic or legislation point of view) to be triggered.

Certain industries (e.g. nuclear, chemical, etc.) have had to define risk acceptability levels using the ALARP (As Low As Reasonably Practicable) approach, which is based on representing the seriousness of consequences in three areas according to their probability (Fig. 1):

1. Area 1, where the risk is considered unacceptable because its frequency is too high or its consequences are too great. Immediate action must be taken to reduce the risk;

2. Area 3, where the risk is no longer perceived and is considered to be acceptable;

3. Area 2 is an intermediary area, where risk is considered to be tolerable. Actions may be taken and justified according to their efficiency and cost.

The notion of acceptability is difficult to interpret and comes up against various legal considerations that are not discussed in this article. However, the ALARP approach is of interest in processing events whose probability of occurrence is not high, which is the case of countries exposed to a moderate level of seismic activity. For example, Switzerland is a country of moderate seismicity, and the verification of the earthquake engineering safety of existing buildings (SIA2018, 2004) takes into account the notion of risk according to the ALARP principle when assessing the need 


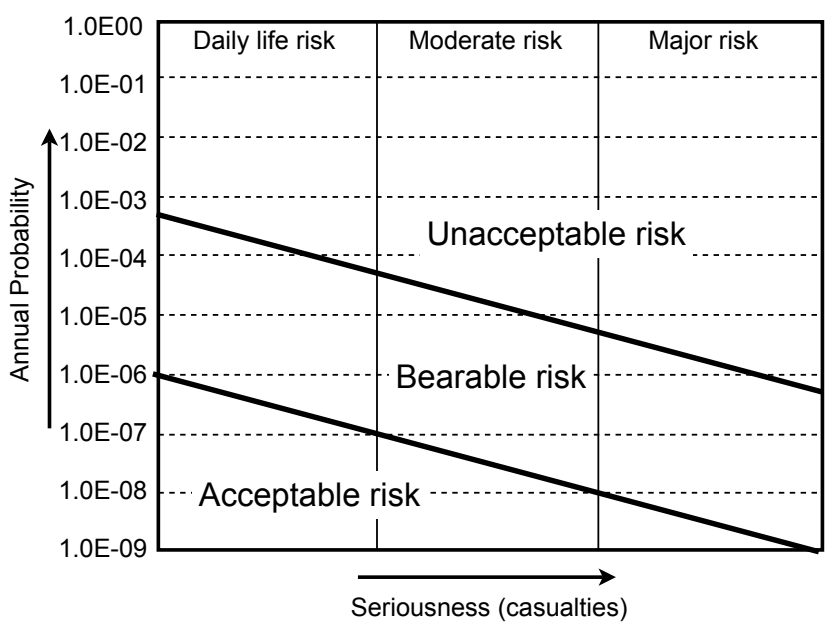

Fig. 1. Representation of the As Low As Reasonably Practicable approach (after Bresse, 2009).

to reinforce the earthquake resistance of buildings. Using an analysis with three levels of increasing accuracy, this approach enables (1) identification of the buildings in need of risk reduction actions and (2) the prioritization of the actions to be implemented. It also enables the various risks (natural or domestic) to be positioned on a single scale and compared, even if the acceptability limit remains difficult to determine since it varies depending on the voluntary or involuntary nature of the risk in question; reasoned policy decisions can thus be taken to reduce overall risk. In zones exposed to natural disasters, this approach also enables the associated risks to be compared and offers guidance for the investment funds available.

In France, this exercise is difficult because of the moderate seismicity level and also because there are no specific French regulations concerning the consideration of risk acceptability. It is estimated, using a Guttenberg-Richter type seismicity model, that on average a quake of a magnitude greater than 5 can be expected every $30 \mathrm{yr}$, and a quake of $6+$ magnitude every $300 \mathrm{yr}$. A contemporary earthquake occurred in Lambesc in 1909, estimated magnitude 6, causing around forty casualties. However, earthquakes are rare. France's seismic risk prevention policy can be seen from two points of view: either the commitment of the public authorities regarding the reduction of seismic risk fails to meet the expected risk, or greater natural or domestic risks exist and the commitment of the public authorities is equal to or greater than the acceptable level. If we can determine the real situation, we can provide policy makers with information to help them to define adequate prevention policies.

This paper proposes an analysis of seismic risk using a probabilistic approach, including regional and local hazards, and the vulnerability assessment of buildings. In the French seismic context, Grenoble is a city of major economic and social importance, being home to a number of sensitive industries (chemical, nuclear, etc.), companies with a strong economic impact on the region, and a large population (approximately 300000 inhabitants). The Northern Alps, where Grenoble is located, has recently experienced moderate earthquakes, some of which (Annecy, $M_{\mathrm{L}}=4.8$ 15 July 1996) caused slight damage. In the national EC8 annex, the seismic level of this region is part of the highest hazard zones (Zone IV) with acceleration $a_{\mathrm{g}}=0.16 \mathrm{~g}$ for $475 \mathrm{yr}$ of return period.

Numerous studies have been carried out in Grenoble over the past $25 \mathrm{yr}$ to improve our knowledge of the seismic risks in this region. They have observed the seismicity of the Alps and the Grenoble area by setting up a seismological surveillance network (Guyoton et al., 1990; Thouvenot et al., 2003), defining homogenous seismotectonic zones for the seismic zoning of France (Martin et al., 2002), adjusting according to the various studies conducted by GEOTER in France since 2002. Other studies have observed, analyzed and identified the areas of the city with major site effects (Lebrun et al., 2001; Cornou et al., 2003; Gueguen et al., 2007a; Pequegnat et al., 2008), characterized also of the urban environment and estimated of the physical vulnerability of the constructions (Gueguen et al., 2007b) and the study of human behavior and the social vulnerability of Grenoble (Gueguen et al., 2009). The method used in this article is based on a probabilistic risk assessment and qualification approach. First, hazard is assessed according to a probabilistic approach, which gives a hazard curve integrating local site effects. Then, the vulnerability of the buildings will be analyzed, giving vulnerability functions and fragility curves. Finally, a probabilistic risk calculation will be proposed integrating hazard, vulnerability and certain loss aspects. The level of seismic risk obtained will then be compared to the level of other risks, particularly domestic risks (e.g. car accidents, sport accidents, etc.), and to conclude, the notion of risk acceptability will be discussed.

\section{Seismic hazard evaluation}

\subsection{Regional hazard}

Grenoble is in the Northern Alps, on the external border of the alpine mountain range. The region observes intense seismic activity and has experienced a number of major, historic earthquakes (Thouvenot et al., 2003). The seismicity here includes (Fig. 2) an active fault along the Belledonne mountain range. This fault causes seismic activity very close to Grenoble, with magnitudes of 3 and more, felt locally by the population and occasionally causing disorder. Major earthquakes have also occurred along this same line, including the historic earthquake of 1962 (Corrençon $M_{\mathrm{L}}=5.3$ ), Faverges in $1980\left(M_{\mathrm{L}}=4.7\right)$, and Grand Bornand in $1994\left(M_{\mathrm{L}}=\right.$ 5.1). Around Grenoble, historic data from the SISFRANCE database (http://www.sisfrance.net/) were analyzed by Levret et al. (1994, 1996). Intensities are given in MSK intensity (Medvedev et al., 1965). Around fifty historic events were 


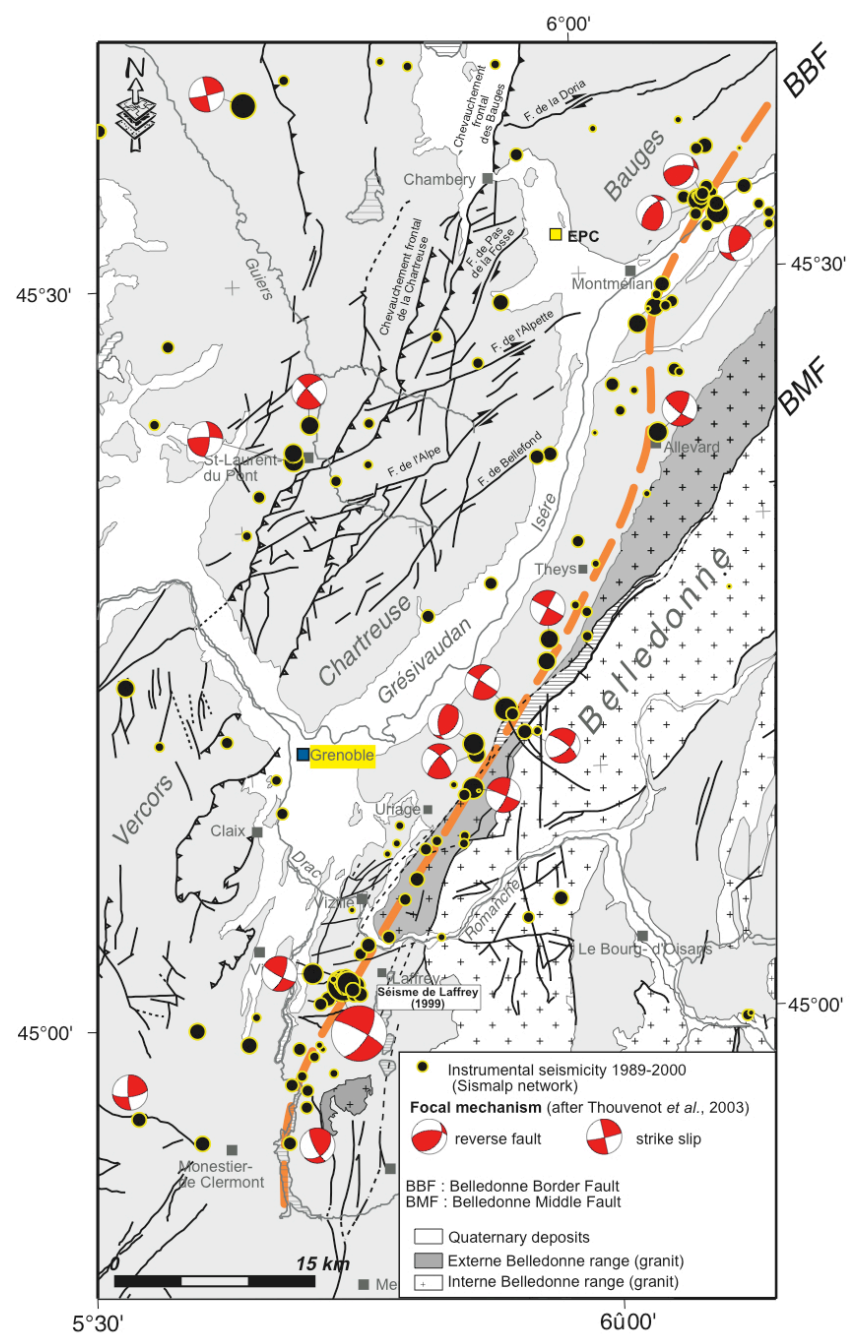

Fig. 2. Map of Grenoble and the main epicenters localized by the regional seismic network SISMALP (after Thouvenot et al., 2003).

located around Grenoble. The depths considered correspond to average depths of the source zones to which they are attached, as defined by the probabilistic zoning of France (Martin et al., 2002). The earthquakes produced intensities of less than V, except for the Gresivaudan earthquake on 7 January 1851 (V-VI in Grenoble, $5 \mathrm{~km} \mathrm{NW}$ of Grenoble), the Corrençon earthquake on 25 April 1962 (about $20 \mathrm{~km} \mathrm{NW}$ of Grenoble) with an epicentral intensity of VII-VIII and the Voreppe earthquake on 12 January 1754 (epicentral intensity VI-VII, $20 \mathrm{~km} \mathrm{NNW}$ of Grenoble). Other more distant but strong intensity quakes have been included in this study, characterizing the level of seismicity of the Northern Alps region to which Grenoble belongs. Table 1 gives the list of major historic events of an intensity of more than $\mathrm{V}$ within the study area.
Table 1. List of historical earthquakes having produced macroseismic intensities over V Northern Alps region in the Grenoble district $\left(I_{0}\right.$ : epicentral intensity, $I$ : macroseismic intensity in Grenoble; Gr: Council of Grenoble; Swz: Switzerland; It: Italy, Fr: France (Source: http://www.sisfrance.net/.

\begin{tabular}{llll}
\hline Date & Region & $I_{0}$ & $I$ \\
\hline 25 April 1963 & Monteynard (Fr) & VII & V \\
25 April 1962 & Corrençon (Gr) & VII-VIII & VI-VII \\
30 May 1946 & Chalais (Swz) & VII & V \\
25 January 1946 & Chalais (Swz) & VII-VIII & V \\
18 July 1938 & Guillestre (Fr) & VI-VII & V \\
23 February 1887 & Imperia-Bussana (It) & IX & VI \\
27 November 1884 & Guillestre (Fr) & VII & V \\
10 December 1882 & Belledonne (Gr) & V & V \\
5 August 1881 & Belledonne (Gr) & VI & V-VI \\
22 July 1881 & Belledonne (Gr) & VII & V \\
25 July 1855 & Visp (Swz) & IX & V \\
3 April 1839 & Domene (Gr) & VI & V \\
19 February 1822 & Bugey (Fr) & VII-VIII & V-VI \\
15 October 1784 & Aix-les-Bains (Gr) & VI-VII & V \\
15 July 1782 & Uriage (Gr) & VI & V \\
\hline
\end{tabular}

\subsection{Probabilistic hazard curve}

The aim of the intensity approach followed in this paper is to reduce the uncertainties in the probabilistic hazard assessment due to the conversion relationships between intensity/magnitude or intensity/acceleration. Moreover, (Beauval et al., 2008) showed that existing methods focusing on testing modeled earthquake occurrences (in magnitude and space) against ground motion observations remain essential, especially for moderately seismic- prone regions. Moreover, in order to estimate the seismic risk, no recent major earthquakes occurred in this region; the only data compiled for the seismic hazard analysis developed here was found in the macroseismic database SISFRANCE. Since most of the empirical methods for assessing seismic vulnerability and damage are given for macroseismic intensities, as was the case for Grenoble (Gueguen et al., 2007b), the seismic hazard assessment is provided in intensity in this paper. In order to take into account the epistemic uncertainties related to the zonings, two alternative seismotectonic models are used: (1) general zoning of France (Martin et al., 2002), based on a simplification of the basic French 52-zone model, produced for the probabilistic seismic hazard study for France (Fig. 3a); (2) a second zoning (Fig. 3b), called GEOTER (Martin et al., 2008), adjusted to the most recent studies of the Northern Alps, enabling the contours of certain areas to be defined more accurately. It is also based on the analysis and integration of more recent data and studies (PALEOIS European project: Evaluation of the potential for large earthquakes in regions of present-day low seismic activity in Europe, SAFE (Slow Active Faults in Europe), GEOFRANCE 3D, ENTEC (Environmental Tectonics, The Northern Alpine 

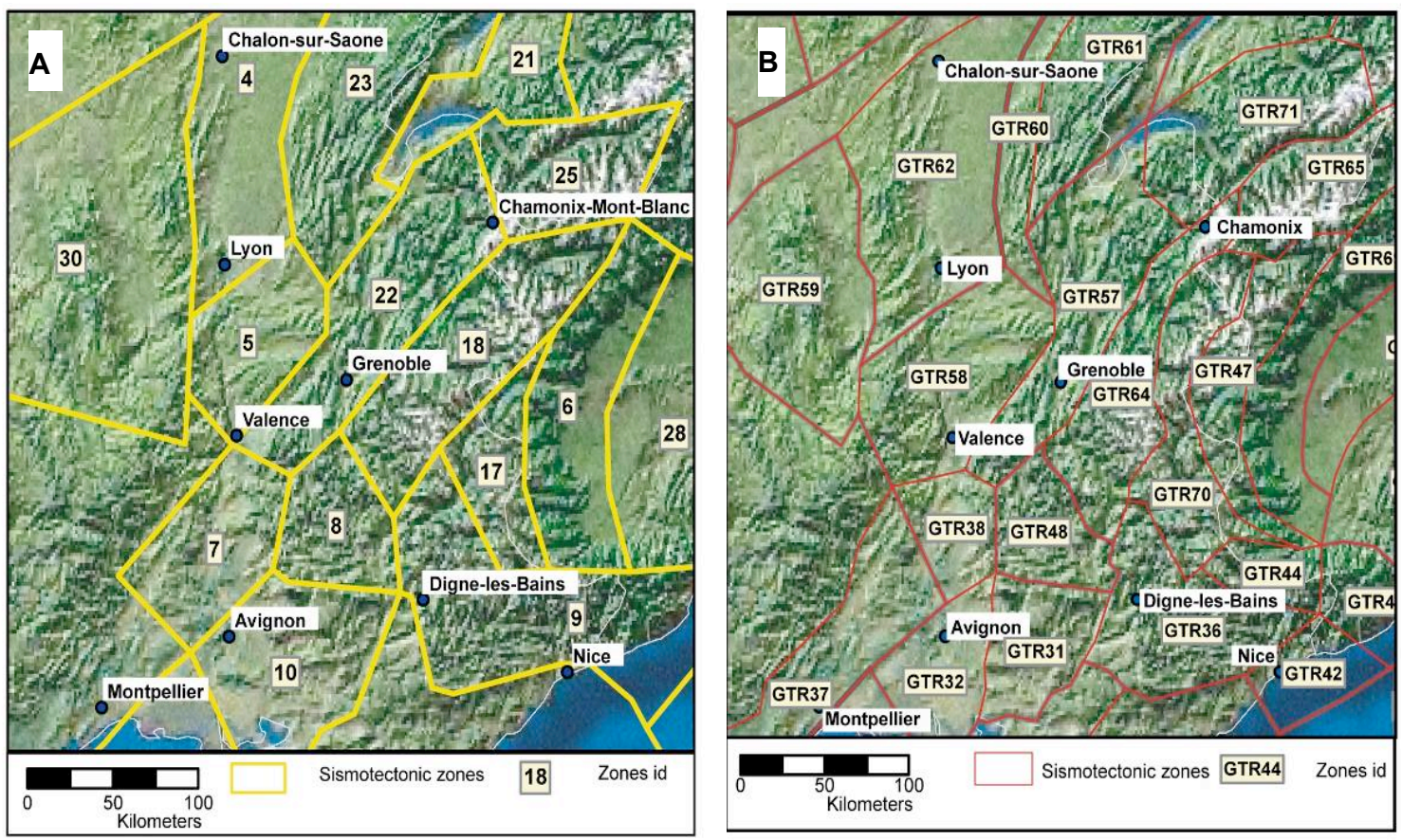

Fig. 3. Seismic zoning of the Grenoble region (A) extracted from the national probabilistic seismic hazard assessment map (Martin et al., 2002) and (B) modified using regional tectonic information by Martin et al. (2008).

Foreland Natural Laboratory). The zones mainly identify the boundaries of the geological units considered as being homogenous in terms of the current constraints field, of the expression of recent deformation, and mostly limited by major tectonic accidents. Table 2 shows the input data used for the GEOTER zoning probabilistic calculation. For each zone, the date and intensity are indicated for the strongest historic earthquakes listed in the SISFRANCE database and the source parameters (Intensity $I_{0}$ minimal and maximal macroseismic intensity, depth corresponding to minimal and maximal intensity). For the Grenoble zone, earthquakes with an epicentral intensity between 5 and 8 at depths between 3 and $15 \mathrm{~km}$ are taken into account.

\subsubsection{Seismicity model}

The seismic parameter calculation of the distribution laws takes completeness periods into consideration. These periods are defined using two methods, the first being the Stepp method (Stepp, 1972) and the second corresponding to a histogram analysis of the number of earthquakes per timewindow for each level of intensity (Martin et al., 2008). The completeness periods used for the Grenoble region for each intensity are: 1920 (IV-V), 1880 (V-VI), 1830 (VI-VII), 1800 (VII-VIII), 1500 (VIII-IX) and 1300 (IX-X). In the Alpine region, it is always possible to define completeness periods, except for intensities VIII and IX, because of the small number of earthquakes. For these levels of intensity, the periods used were obtained from the full catalogue for the whole of France. For intensity IX, the date 1300 was used in order to take the Basel/Mulhouse (Northern Alps zone) earthquake into account in the adjustments. The model used to define seismicity distribution is a Gutenberg-Richter type of Poisson's model, giving the annual rate of occurrence for each intensity. The calculation of the adjustment parameters for the Gutenberg-Richter curves uses Weichert's maximum likelihood method (Weichert, 1980), well-suited to the variable completeness periods and enabling quantification of the uncertainties associated with the adjusted parameters. For most of the zones, the seismicity samples suffice to calculate the zones' seismic parameters. If not, several zones are grouped together to enable the adjustment. The calculated gradient is then set for the grouped zones, while the rate of activity is divided proportionally to the zones' surface areas. For the statistical calculation of the GuttenbergRichter's law seismic parameters a and b, intensity intervals of 0.5 are used. For each source zone, Grenoble's completeness periods are used, corresponding to the large geographic zone to which the seismic zone is attached, i.e. the Alps. The minimal intensity for the adjustment calculation is $I_{\min }=\mathrm{IV}$. Adjustment of the distribution laws based on this threshold enables integration of the largest possible seismicity sample and thus compensates for the small size of the source zones and lack of data. If the adjustments obtained are not satisfactory, other minimal intensity values are used $\left(I_{\min }=\mathrm{IV}-\mathrm{V}, \mathrm{V}\right.$, $\mathrm{V}-\mathrm{VI}$ or VI). These minimal intensities are independent of the minimal intensities used for the seismic hazard calcula- 
Table 2. Parameters of the seismic zones used for the probabilistic assessment in the Grenoble zone (GTR57) with the GEOTER zoning (Martin et al., 2008). Code: code of the zone, MHE: Major Historical Earthquake of the zone; SP: Source parameters; Date: date of the MHE; $I_{0}=$ Epicentral intensity of the MHE; Loc-Int: quality of the historical information for the location and the intensity of the MHE (A: high quality; $\mathrm{K}$ : very low quality); $I_{i}$ : Minimal macroseismic intensity of the zone; $I_{a}$ : Maximal intensity of the zone; $H_{i} / a$ : Minimal and maximal depth of the seismic source in the zone. Intensities are given in MSK scale.

\begin{tabular}{|c|c|c|c|c|c|c|}
\hline \multirow{2}{*}{$\begin{array}{l}\text { Code } \\
\text { XX }\end{array}$} & \multicolumn{3}{|c|}{ MHE } & \multicolumn{3}{|c|}{ SP } \\
\hline & Date & $I_{0}$ & Loc/Int & $I_{i}$ & $I_{a}$ & $H_{i} / a$ \\
\hline GTR31 & 11 Jun 1909 & VIII-IX & $\mathrm{A} / \mathrm{A}$ & $\mathrm{V}$ & IX & $3-16$ \\
\hline GTR32 & 18 Nov 1769 & VII & $\mathrm{D} / \mathrm{B}$ & $\mathrm{V}$ & VII-VIII & $3-16$ \\
\hline GTR36 & $\begin{array}{l}20 \text { Jul } 1564 \\
18 \text { Jan } 1618 \\
15 \text { Feb } 1644 \\
12 \text { Dec } 1855\end{array}$ & VIII & $\begin{array}{l}D / C \\
D / C \\
C / C \\
C / B\end{array}$ & $\mathrm{~V}$ & VIII-IX & $5-15$ \\
\hline GTR37 & 28 Jun 1950 & VI-VII & $\mathrm{A} / \mathrm{K}$ & $\mathrm{V}$ & VII & $5-15$ \\
\hline GTR38 & $\begin{array}{l}23 \text { Jan } 1773 \\
19 \text { Jul } 1873 \\
8 \text { Aug } 1873\end{array}$ & VII-VIII & $\begin{array}{l}\mathrm{C} / \mathrm{A} \\
\mathrm{A} / \mathrm{A} \\
\mathrm{A} / \mathrm{B}\end{array}$ & V & VIII & $3-10$ \\
\hline GTR42 & 29 Dec 1854 & VII-VIII & $\mathrm{B} / \mathrm{C}$ & $\mathrm{V}$ & VIII & $5-15$ \\
\hline GTR43 & 23 Feb 1887 & IX & $\mathrm{C} / \mathrm{K}$ & $\mathrm{V}$ & IX-X & $5-15$ \\
\hline GTR44 & 7 Apr 1966 & VI-VII & $\mathrm{A} / \mathrm{A}$ & $\mathrm{V}$ & VII & $5-15$ \\
\hline GTR45 & 30 May 1905 & VI & $\mathrm{B} / \mathrm{B}$ & $\mathrm{V}$ & VI-VII & $5-15$ \\
\hline GTR46 & 25 May 1901 & VI & $\mathrm{B} / \mathrm{B}$ & $\mathrm{V}$ & VI-VII & $5-15$ \\
\hline GTR47 & 12 Sep 1785 & VII-VIII & $\mathrm{D} / \mathrm{C}$ & $\mathrm{V}$ & VIII & $5-15$ \\
\hline GTR48 & 19 May 1866 & VII-VIII & $\mathrm{C} / \mathrm{K}$ & $\mathrm{V}$ & VIII & $3-8$ \\
\hline GTR49 & 18 Oct 1833 & VII & $\mathrm{D} / \mathrm{B}$ & $\mathrm{V}$ & VII-VIII & $5-15$ \\
\hline GTR57 & $\begin{array}{l}19 \text { Feb } 1822 \\
25 \text { Apr } 1962\end{array}$ & VII-VIII & $\begin{array}{l}\mathrm{B} / \mathrm{B} \\
\mathrm{A} / \mathrm{A}\end{array}$ & V & VIII & $3-15$ \\
\hline GTR58 & 18 Feb 1889 & VI-VII & $\mathrm{D} / \mathrm{B}$ & $\mathrm{V}$ & VII & $5-15$ \\
\hline GTR59 & 29 Jun 1477 & VII-VIII & $\mathrm{C} / \mathrm{B}$ & $\mathrm{V}$ & VIII & $5-15$ \\
\hline GTR60 & 9 Sep 1879 & VI & $\mathrm{D} / \mathrm{B}$ & $\mathrm{V}$ & VI-VII & $3-15$ \\
\hline GTR61 & $\begin{array}{l}17 \text { Aug } 1846 \\
21 \text { Jun } 1971\end{array}$ & VII & $\begin{array}{l}\mathrm{D} / \mathrm{B} \\
\mathrm{A} / \mathrm{A}\end{array}$ & $\mathrm{V}$ & VII-VIII & $3-15$ \\
\hline GTR62 & 24 Jun 1878 & VI & $\mathrm{B} / \mathrm{B}$ & $\mathrm{V}$ & VI-VII & $5-15$ \\
\hline GTR63 & 27 Jan 1881 & VII & $\mathrm{D} / \mathrm{C}$ & $\mathrm{V}$ & VII-VIII & $3-8$ \\
\hline GTR64 & $\begin{array}{l}11 \text { Mar } 1817 \\
\text { 22 Jul } 1881 \\
\text { 13 Aug } 1905 \\
25 \text { Apr } 1963\end{array}$ & VII & $\begin{array}{l}\mathrm{D} / \mathrm{A} \\
\mathrm{C} / \mathrm{B} \\
\mathrm{C} / \mathrm{B} \\
\mathrm{A} / \mathrm{A}\end{array}$ & $\mathrm{V}$ & VII-VIII & $5-15$ \\
\hline GTR65 & $25 \mathrm{Jul} 1855$ & IX & $\mathrm{B} / \mathrm{A}$ & $\mathrm{V}$ & IX-X & $5-15$ \\
\hline GTR70 & 5 Apr 1959 & VII-VIII & $\mathrm{B} / \mathrm{B}$ & $\mathrm{V}$ & VIII & $5-15$ \\
\hline GTR71 & 29 Apr 1905 & VII-VIII & $\mathrm{B} / \mathrm{B}$ & $\mathrm{V}$ & VIII & $3-8$ \\
\hline
\end{tabular}




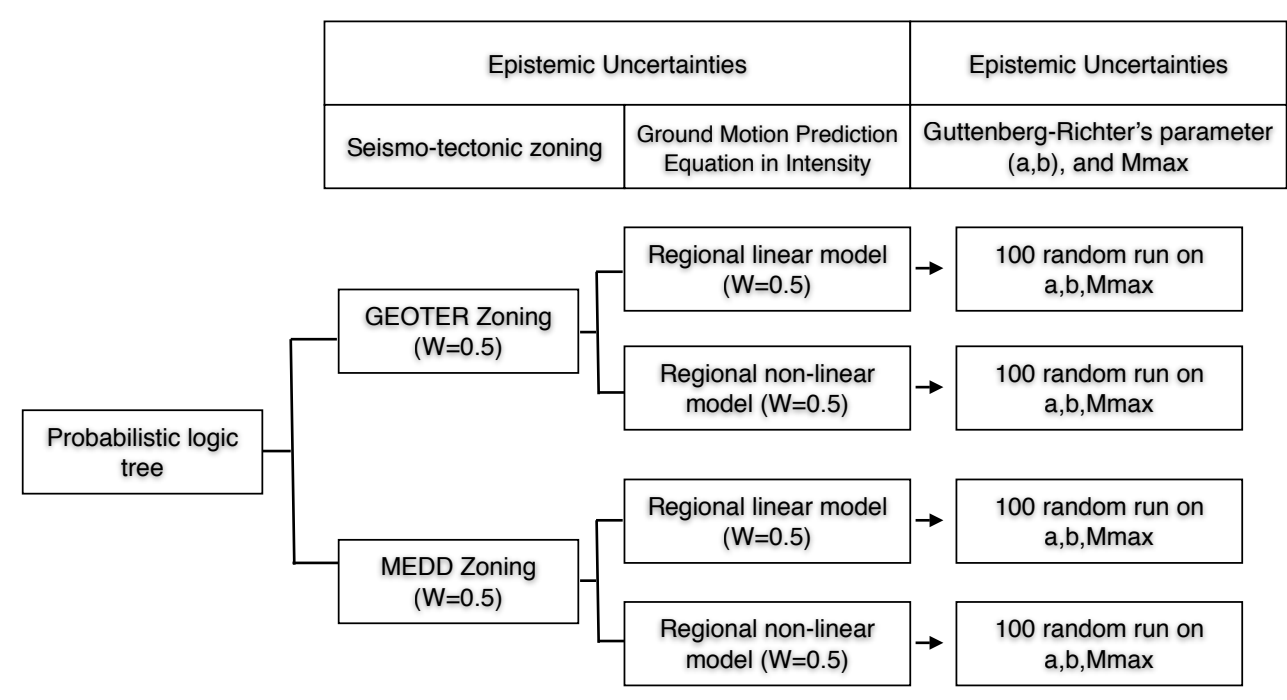

Fig. 4. Logic tree of the probabilistic hazard assessment method used for assessing and accounting for the uncertainties (after Martin et al., 2008).

tions. The annual activity rate values for each source zone are therefore systematically reduced to the minimal intensity of the seismic hazard calculation. Generally speaking, in each source zone of the two zonings, a series of adjustments is applied according to different intensity intervals and different minimal intensities. The best adjustment is chosen on the basis of the following criteria:

- Calculation of $a$ and $b$ Guttenberg-Richter's parameters and associated standard deviations. The adjustments resulting in the smallest standard deviations are preferred.

- The gradient of the adjustment must remain within the range $0.25-0.75$.

- The adjustment between the distribution law and the seismicity data must be satisfactory.

Finally, adjustment coherency is checked to make sure that the annual activity rates per intensity interval cumulated for all sources coincide with the catalogue rates for the study zone.

\subsubsection{Empirical macroseismic intensity prediction model}

Arracoucau et al. (2006) defined an overall attenuation model for the whole of France based on points in time from the SISFRANCE database (sample of 1000 points in time). Considering all the data, the sample includes a larger number of low intensities and there is a risk of influencing the attenuation model because of the greater weighting associated with low intensities. The model was adjusted to the data using the least-squares method. Several sensitivity tests were carried out (Martin et al., 2008), not described here, to enable verification of this adjustment. They led to the proposal of a linear type model (Eq. 1) and a non-linear type model (Eq. 2) for the Alps region:

$I_{0}-I=-0.3209-0.019 R_{\mathrm{epi}}+1.6938 \log _{10}\left(R_{\mathrm{epi}}\right)$

where $\sigma=0.91$.

$$
\begin{aligned}
& \triangle I \quad=I_{0}-I=3.4 \log _{10}\left(\frac{\sqrt{R_{\mathrm{epi}}^{2}+11.72^{2}}}{11.72}\right) \\
& +3.410^{-5} \log _{10}(e)\left(\sqrt{R_{\mathrm{epi}}^{2}+11.72^{2}}-11.72\right)
\end{aligned}
$$

where $e$ means the Neper's constant (2.718) and $\sigma=1.04$. In both equations, $I$ and $I_{0}$ are the macroseismic and epicentral intensities, respectively, $R_{\text {epi }}$ the epicentral distance and $\sigma$ the standard deviation.

\subsubsection{Probabilistic calculation}

The probabilistic seismic hazard (PSHA) is calculated by following the branches of a logical decision tree, as proposed by Bommer et al. (2005), to take uncertainty into account. All the branches of the logic tree in Fig. 4 are tested for each of the 100 random parameter combinations at each point of the grid. In all, 400 simulations were carried out, each one resulting in a hazard calculation. Each calculation consisted in determining the annual exceedance probability of a series of intensities and providing a hazard curve. Taking into account the weightings of the logic tree branches, statistical processing enables the results and their distribution to be expressed as three hazard curves, associated with median, $15 \%$, and $85 \%$ percentiles of annual probability distributions. Exploitation of the hazard curves at each point of the grid enables definition of the intensities associated with a return period by interpolating the values on the hazard intensity curves. Similarly, the results and their distribution 


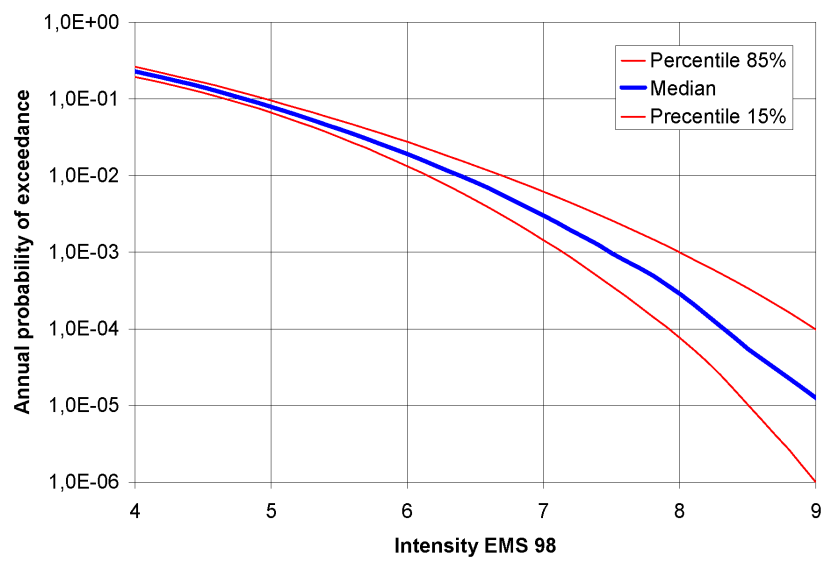

Fig. 5. Hazard curve in intensity for the Grenoble district given the annual probability of exceedance of EMS98 intensity.

are expressed by the median and $15 \%$ and $85 \%$ percentile statistical values. For applying the vulnerability methods defined using the European Macroseismic Scale 98 (EMS98, Grunthal and Levret, 2001) for intensity, the PSHA curve are converted from MSK (SISFRANCE catalog) to EMS98, as proposed by Musson et al. (2010) who assume a direct equivalence. Thus, Fig. 5 shows that the return periods of macroseismic intensity VI (beginning of damage) is around $10^{-2}$, and $10^{-4}$ for intensity VIII. These values are relatively similar to those proposed by the magnitude methods. In Grenoble, intensity having annual probability of 0.002 (475 of return period) is VII-VIII.

\subsection{Local hazard}

Grenoble lies in a Y-shaped sediment basin, which has experienced several fill periods (Nicoud et al., 2002). The thick filling causes considerable amplification of the seismic ground motion (Lebrun et al., 2001) (Gueguen et al., 2007b) (Pequegnat et al., 2008) within a frequency range of $0.3 \mathrm{~Hz}$ to $10 \mathrm{~Hz}$. Seismic ground motion also varies due to the last few meters of fill which, according to Lebrun et al. (2001) and Gueguen et al. (2007b), produce amplifications in the highest frequencies $(3-10 \mathrm{~Hz})$. This frequency range affects Grenoble's buildings since most have a resonance frequency within this same range (Farsi and Bard, 2004; Michel et al., 2010), causing a situation in which damage can also be amplified (e.g. Anderson et al., 1986; Gueguen et al., 1998).

Some authors propose intensity increments according to the type of terrain (e.g. Mevedev et al., 1962; Astorza and Monje, 1991). There is no formal microzoning of the Grenoble valley; however, measurements based on seismic background noise (the HVSRN background noise H/V method) enable identification of the zones with variable amplifications, which may be related to the most superficial formations in particular (e.g. Gueguen et al., 2000). Using this method and the sedimentary fill analysis, fills can be

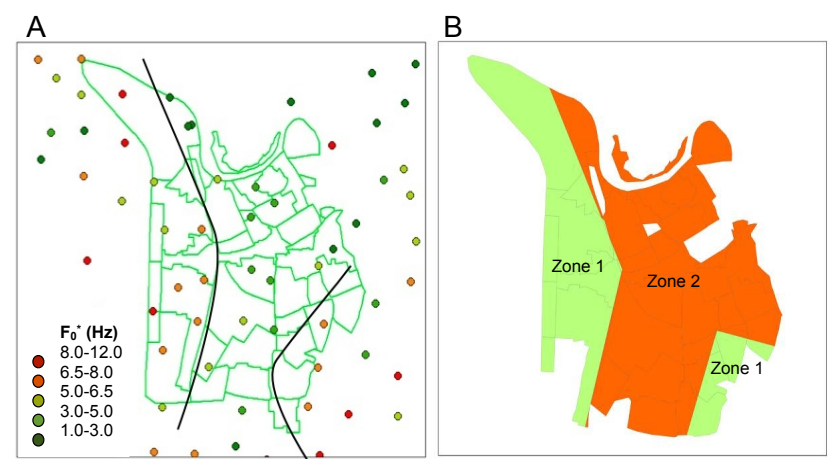

Fig. 6. (A): Amplified frequency between 1 and $15 \mathrm{~Hz}$ observed in the Grenoble district by the $\mathrm{H} / \mathrm{V}$ spectral ratio using seismic noise. The black lines correspond to the boundaries between the gravel/sandy sediment and the silt/clayed sediments, both having been brought by the flooding of the Drac (West) and the Isere (East) rivers. (B): Rough EC8 classification of the two zones in the district of Grenoble following the amplified frequency map (Zone 1: class B with $\Delta I=0.7$; Zone 2 : class $\mathrm{C}$ with $\Delta I=1.5-\Delta I$ is the increment of intensity depending on the soil classification and following Astorza and Monje, 1991).

distinguished (Fig. 6a) (1) in the West and South-east with frequencies over $6 \mathrm{~Hz}$ corresponding to gravel fills, (2) in the centre and in the East of the city with frequencies of around $1-5 \mathrm{~Hz}$ corresponding to high clay fills (sometimes including peat) and which generate major site effects because of a strong impedance contrast. This paper proposes to define the limits of the zones approximately according to HVSRN measurements. This gives two large zones (Fig. 6b): zone 1 comprising type B soils (sand and gravel) and zone 2 with type C soils (silt and clay), according to the EC8 classification. The correlation coefficients of macroseismic intensities are then taken from Astorza and Monje (1991), choosing average values: for zone 1 , the hazard calculated for rock site, and expressed in macroseismic intensity, will be incremented by 0.7 ; for zone 2 , the calculated hazard will be incremented by 1.5 . These weighted intensities will then be assigned to each urban area, since this is the geographic unit of interest.

\section{Seismic vulnerability assessment}

The first signs of habitation of the Grenoble area date back to $450 \mathrm{BC}$, but the town really started to develop in the sixteenth century, growing in a number of stages (Parent, 1982). Prior to the nineteenth century, the city's walls limited the development and urbanization of the surrounding basin. Around 1850 , the population increased and the city spread beyond the walls, which were destroyed in about 1910 . With the city's industrialization, a new urbanization phase began towards the west and south. So-called expansion suburbs developed to the south, and these suburbs continued to grow until about 1945. During this period, the use of reinforced concrete 
started to become widespread, assisting the 1945-1970 period with the largest urban expansion ever experienced by the city, particularly in the southern suburbs. A previous study (Gueguen et al., 2007b) identified the types of construction and their distribution throughout Grenoble, according to local specificities and national building developments (such as design codes in particular). This study shows that the city centre is mainly built in masonry (the nearby mountain quarries providing limestone materials). The peripheral suburbs were mainly built using reinforced concrete with frame designs before 1965 and shear walls after 1970. Finally, the expansion suburbs are highly heterogeneous, mixing private housing and collective residential buildings, concrete and masonry constructions, built during different periods (Fig. 7).

The successive waves of demographic increase systematically led to a demand for public institutions, such as schools. In all, 15 schools were built within fifteen years during the most remarkable period after the 1960s. Experience has shown that schools are public buildings which have a major impact on society in the event of seismic damage: if schools suffer during an earthquake, education is interrupted, society's organization is affected and fallback sites are no longer available. Furthermore, schools are more liable to suffer irreversible damage by their specific design and their function (Augenti et al., 2004): asymmetry is almost systematic because of covered playgrounds or long lines of classrooms along one side, which appears to increase vulnerability in constructions mainly built before the application of earthquake engineering rules. Attention is therefore given particularly to such buildings in this paper.

The VULNERALP method (Gueguen et al., 2007b) was developed in Grenoble, adapting the methods used in highly seismic countries. A certain similarity between old Italian and French constructions (particularly in terms of masonry) enabled us to base our method on the GNDT method (GNDT, 1993; Seismocare, 1998). This method consists in identifying the probable weaknesses of the constructions in the event of an earthquake and assigning them a vulnerability index, based upon the damage observed after destructive earthquakes in Italy. GNDT values were used in the VULNERALP method because France has no such documented records corresponding to seismic damage. In the VULNERALP method (Gueguen et al., 2007b), each vulnerability index IV is associated with a vulnerability curve found in GNDT method, which enables determination of an average damage value $\left(\mu_{\mathrm{D}}\right)$ according to the EMS98 damage scale, according to a given macroseismic intensity ( $\left.I_{\mathrm{EMS}}\right)$ :

$\mu_{\mathrm{D}}=0.5+0.45 \operatorname{atan}\left(0.55\left(I_{\mathrm{EMS}}-10.2+0.05 \mathrm{IV}\right)\right)$

The construction typologies used in VULNERALP are the same as those described in EMS98. This strategy means that vulnerability can be linked to a damage level compatible with that of EMS98 (Gueguen et al., 2007b). Matrices are then available, with the intervals of probable values [IV-; IV+] taken from the GNDT criteria and values. The

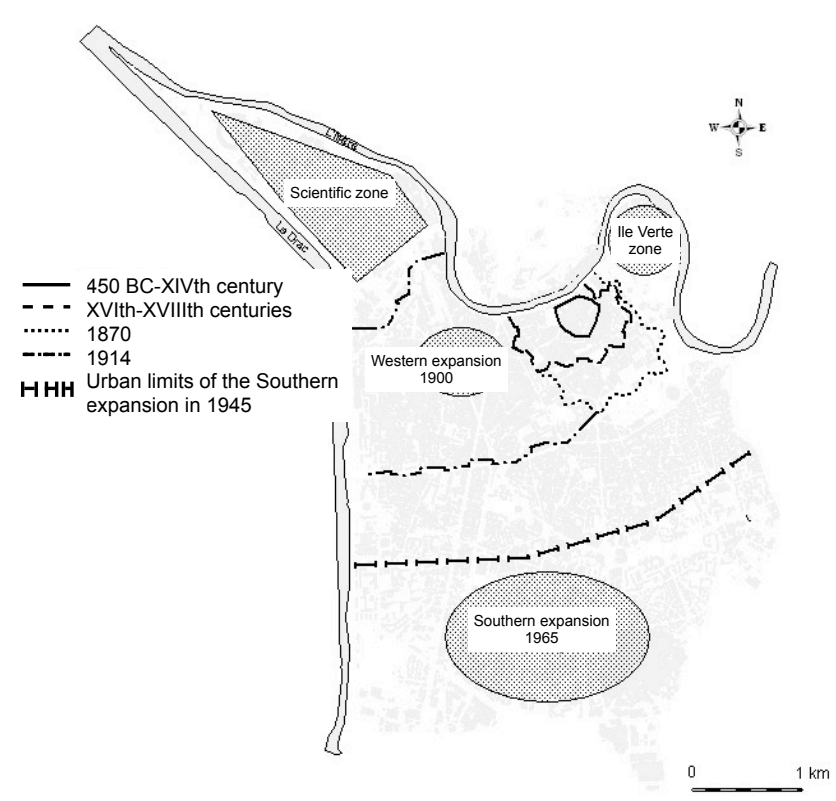

Fig. 7. Urbanization of the Grenoble district since $475 \mathrm{BC}$, including the most urbanization policies in 1870, 1914, 1945 and 1965.

distribution of the typologies and criteria used in the VULNERALP method was obtained by way of surveys among random itinerary in the areas previously defined as being homogeneous (Gueguen et al., 2007b). The damage scale used, the European Macroseismic Scale (EMS-98) (Grunthal and Levret, 2001), characterizes the damage level on a discrete 5-level scale $\left(\mathrm{D}_{k}\right.$ for $\left.k=0,1,2,3,4,5\right)$. The vulnerability curves enable characterization of an average damage value $\left(\mu_{\mathrm{D}}\right)$, representing the mean damage for buildings of the same vulnerability indexes subjected to a given intensity. To take into account the variability of damage levels $k$, damage distribution around average damage $\mu_{\mathrm{D}}$ is considered. Some authors have shown that this distribution can be evaluated by a binomial distribution (Milutinovic and Trendafiloski, 2003), (Lagomarsino and Giovinazzi, 2006) (Eq. 5), adjusted to experience feedback from major Italian earthquakes:

$p\left(D_{k}\right)=\frac{5 !}{k !(5-k)}\left(\frac{\mu_{\mathrm{D}}}{5}\right)^{k} \times\left(1-\frac{\mu_{\mathrm{D}}}{5}\right)^{5-k}$

It is therefore possible to calculate the probability distribution of observing each level of damage $k$ according to EMS98 (D1, D2, D3, D4 and D5) for each average damage level in Eq. (4) $\left(\mu_{\mathrm{D}}=1,2,3\right.$ or 4$)$. This gives the distribution of damage levels for a set of homogeneous buildings, or the probability of observing each level of damage for a specific building. For example, an average damage value $\left(\mu_{\mathrm{D}}\right)$ of 2 (vulnerability index 66, intensity 6.5 ) gives a probability of $26 \%$ of level D1 damage, $34 \%$ of level D2 damage, $23 \%$ of level D3 damage and $17 \%$ for other damage levels. Using Eqs. (3) and (4), the vulnerability curves and damage distributions are combined to give damage probability distribution 


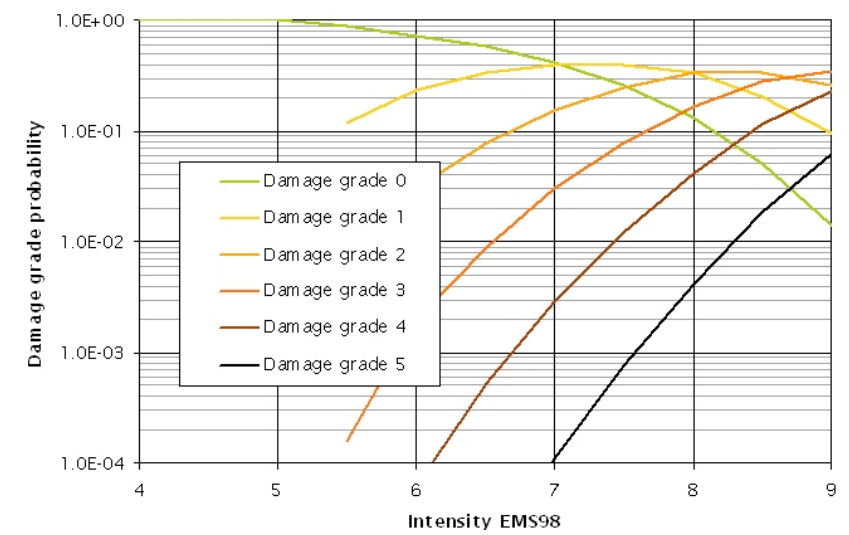

Fig. 8. Example of probability curves of occurrence for each grade of EMS98 damage computed following the VULNERALP approach (Gueguen et al., 2007b) for a given EMS98 intensity and a given vulnerability index (in this example IV $=30$ ).

curves. This then gives the probability of reaching each level of damage (D0, D1, D2, D3, D4 and D5) for different intensities and for a given vulnerability index (Fig. 8). At this stage, the hazard is not part of the risk probability evaluation since hazard probability has not yet been introduced. The initial exercise of this project, i.e. evaluation of the seismic risk in Grenoble, would not be complete without estimating the impact of damage on the populations. Certain links are available in the literature, again, based on past experience (e.g. (Coburn and Spence, 2002). There are two different types of loss in our study: the occupants (1) and the building (2). ((Loss 1) The consequences of an earthquake on the occupants are assessed based on the probability of a fatality among the building's occupants. Assessing the number of victims is highly complex since experience shows that this number can vary significantly. Authors have however reported that building collapse (EMS98 damage level D5) is the main cause of death (75-95\% of deaths, according to Coburn and Spence (2002). The method used here is based on the following equation and results in a mortality rate $\left(M_{\mathrm{R}}\right)$ in the event of collapse (i.e. damage level D5):

$M_{\mathrm{R}}=M_{2} \times M_{3} \times\left(M_{4}+M_{5}\left(1-M_{4}\right)\right)$

where $M_{2}$ is the rate of building occupancy at the time of the earthquake (0.5), $M_{3}$ is the rate of occupants trapped by the collapse (0.6), $M_{4}$ is the mortality rate during collapse $(0.4)$ and $M_{5}$ is the mortality rate after collapse $(0.7)$. The rates used here (in brackets) are the average rates adopted for the project, proposed by Coburn and Spence (2002). The final mortality rate is $M_{\mathrm{R}}=0.25$ for each of the occupants of the buildings affected by a damage level D5. $M_{\mathrm{R}}$ represents the individual probability of death if D5 type damage occurs. In order to take into account the variability of this rate, an set error rate of $\pm 10 \%$ is considered. Writing $P(D 5)$ the probability of a building being at a damage level D5, the $P_{M}$ individual mortality probability of a building's occupant is:

$P_{M}=P(D 5) \times M_{\mathrm{R}}$

(Loss 2) The building loss is represented according to the level of damage observed in the event of an earthquake. According to EMS98, damage D2 corresponds to the first grade of damage (i.e. slight damage). Probability $P(\mathrm{D} \geqslant \mathrm{D} 2)$ of exceeding or equalling damage level D2, i.e. the probability of observing at least slight damage is given by:

$P(\mathrm{D} \geqslant \mathrm{D} 2)=p(\mathrm{D} 2)+p(\mathrm{D} 3)+p(\mathrm{D} 4)+p(\mathrm{D} 5)$

\section{Risk assessment}

Risk is evaluated by developing a comprehensive probabilistic approach, by convoluting the hazard, vulnerability and loss curves. This approach enables evaluation of risk, taking into account the probability of occurrence of all the intensities (from low to high) and enables risk to be quantified according to the different acceptability thresholds, which is the purpose of this paper. In this paper, since the risk is based only on the exceedance probability of two damage levels, i.e. D2 corresponding to at least slight damage and D5 for mortality, the annual probability $P_{y}\left(D_{k}\right)$ of occurrence corresponding to each EMS98 damage level $\mathrm{D}_{k}$ is given by:

$P_{y}\left(\mathrm{D}_{k}\right)=\int_{0}^{\infty} P_{y}\left(I_{\mathrm{EMS} 98}\right) \times p\left(\mathrm{D}_{k}\right) d I_{\mathrm{EMS} 98}$

where $P_{y}\left(I_{\mathrm{EMS}} 98\right)$ is the annual occurrence probability of EMS98 intensity and $p\left(\mathrm{D}_{k}\right)$ is the occurrence probability of the damage level $\mathrm{D}_{k}$ for a given intensity $I_{\mathrm{EMS}} 98$ as provided by Eq. (4). $P_{y}\left(I_{\mathrm{EMS} 98}\right)$ may be deduce from the annual probability of exceedance $P_{y e}$ computed for Fig. 5, for each intensity increment $d I_{\mathrm{EMS} 98}$, using the following equation:

$P_{y}\left(I_{\mathrm{EMS} 98}\right)=P_{y e} \times d I$

Finally, for risk assessment corresponding at least to damage $\mathrm{D} 2$, the exceedance probability $P(\mathrm{D} \geqslant \mathrm{D} 2)$ is the sum of the occurrence probability for each damage $\left(D_{k}, k \geqslant 2\right)$ (Eq. 7).

The notion of risk acceptability was proposed by the Swiss (SIA2018, 2004) to enable decisions to be made regarding the reinforcement and renovation of existing buildings according to an acceptable risk level (ALARP method). This approach, in a moderate seismicity country, offers the advantage of setting about renovation work without necessarily aiming for conformance with equivalent earthquake engineering rules for new constructions. Risk is thus evaluated in two stages: evaluation of the probability of observing each of the damage levels based on hazard and vulnerability and then risk evaluation for the different losses considered (i.e. individual mortality and damage). 


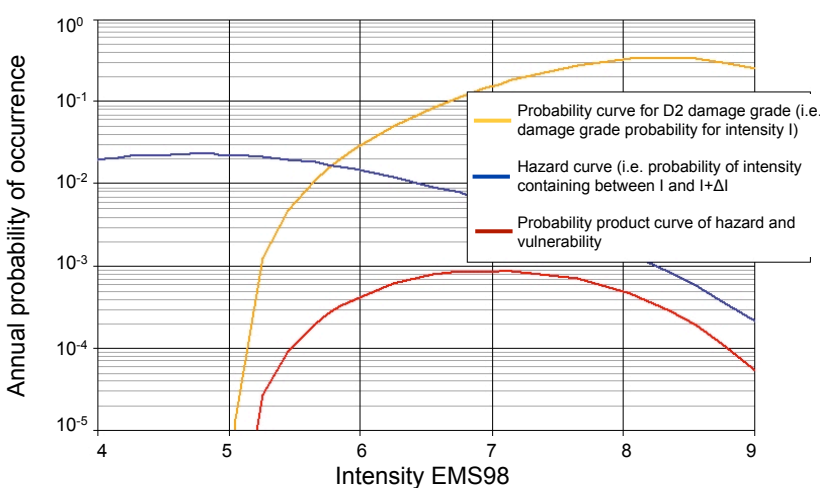

Fig. 9. Probability curve for D2 damage grade for building having IV $=30$ for a given seismic intensity (yellow), annual probability curve of exceedance for seismic hazard in intensity (blue) and probability product of the hazard and vulnerability, i.e. seismic risk probability curve (red).

According to the probabilistic approach, we consider all the possible combinations of intensity and damage probabilities for each intensity. Figure 9 illustrates the seismic risk computing detailed before. It shows the product of hazard probability and damage probability. In this example, the area under the red curve is equivalent to the annual probability of observing D2 level damage. Finally, for each damage level (D0 to D5) and for each vulnerability index IV, this annual probability can be calculated as shown in Fig. 10. Uncertainties can be considered at the various stages of the calculation process. A logical tree is used for seismic hazard, resulting in different curves and a median value, enabling the calculation of 15 and 85 percentiles. The VULNERALP vulnerability analysis method proposes maximum and minimum vulnerability indexes to take into account the epistemic variability of the estimation, due to the assignment of a standard behavior model for each building (Spence et al., 2003). The average variability observed on the study's vulnerability indexes is +40 and -20 for average indexes of 25 . These different uncertainties are added up during the risk calculation process, combining the different values: 3 random event values (15\% percentile, median and $85 \%$ percentile) and 3 vulnerability values (minimum, mean and maximum values).

\section{Discussion on the Grenoble test-bed site}

The risk study has been undertaken on Grenoble's agglomeration, considering an average vulnerability index for each area of homogeneous typology (37 areas) and for schools, considering a vulnerability index for each school (73 schools). Local hazard is taken into account for each area and for each school, according to their respective positions, integrating site effects. If certain areas overlap different local hazard zones, variability is taken into account by subdividing the areas. Risk is calculated over three periods:

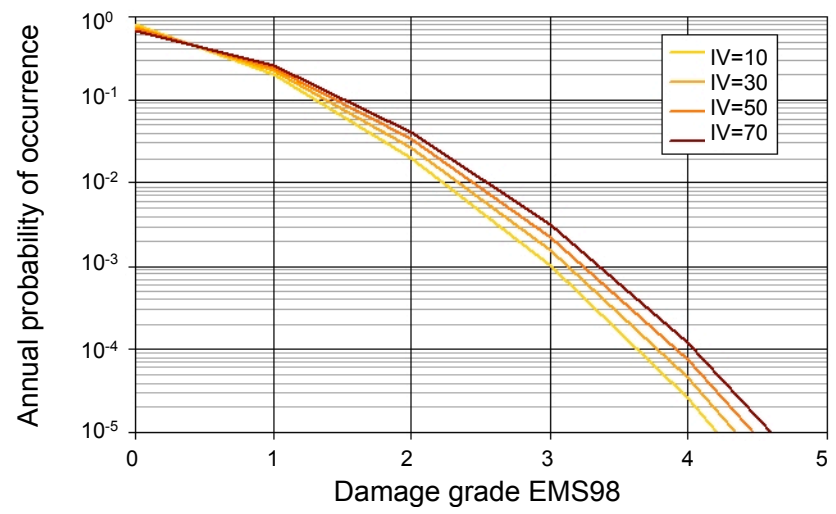

Fig. 10. Seismic probabilistic assessment given the annual probability for observing each EMS98 damage grade $\mathrm{D}_{k}$ in the Grenoble district considering the cumulative annual probability to observe each seismic intensity, for several vulnerability index IV.

(1) one year, corresponding to the probability period generally considered for the presentation of domestic risks (road, industrial accidents, etc...); (2) $50 \mathrm{yr}$, which is the lifetime generally applied to a building; and (3) $100 \mathrm{yr}$, which corresponds more or less to the one human generation. The calculations were repeated 9 times for each probability period to consider all the possible pairs of hazard (median, $15 \%$ and $85 \%$ percentiles) and vulnerability (mean, minimum and maximum values). Human loss is represented by the individual mortality probability and building loss is represented by the probability of exceeding the damage levels D2 and D5, where D2 is equivalent to the loss of building operability and D5 its collapse, each time for the three periods. Only the results corresponding to the one year and $50 \mathrm{yr}$ period for damage levels D5 and D2 are shown here (Figs. 11, 12, $13,14)$, but all the other figures are available in the Supplement. The possible values of vulnerability and damage estimations systematically vary more than those of hazard estimates. This is a direct consequence of the vulnerability estimation using a basic method (VULNERALP, Gueguen et al., 2007b). This is also a direct consequence of the lack of information describing existing structures, one of the more important source of uncertainties (epistemic) of fragility curves (Spence et al., 2003). Although this method implies high uncertainty, it offers the advantage of being able to provide an initial representation of vulnerability on the scale of the city, specifically in a moderate seismic context. However, as mentioned by Spence et al. (2003), we must bear in mind that the greatest proportion of uncertainty in estimating damage is epistemic in origin because of the need to classify each construction according to a generic behavior model, even though very little information is available. These uncertainties could be reduced by changing the way in which they are spread over the risk estimation. Indeed, this method of calculating uncertainties by adding them up results in uncertainty being maximized in the end result. For a complete probabilistic calculation, a logical tree could be used with different branches 


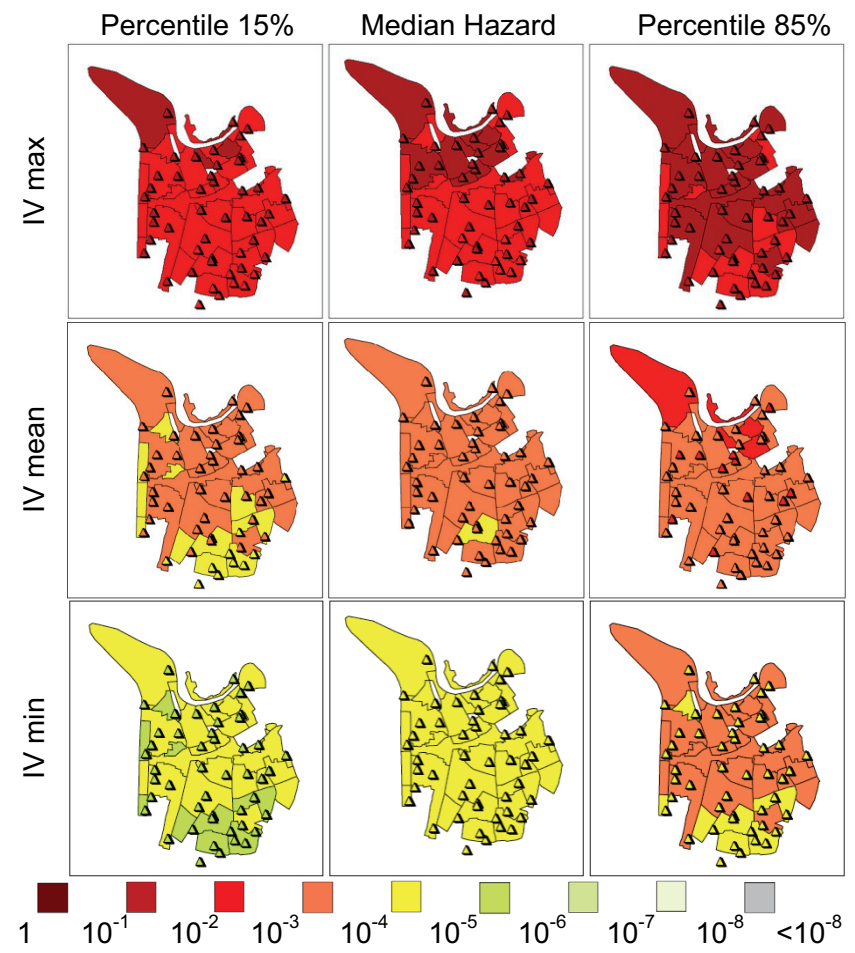

Fig. 11. Annual probability of exceedance for damage grade D2. On each figure, the median value \pm standard deviation corresponding to the hazard curves (from left to right) and the vulnerability assessment (from top to bottom) are displayed. The triangle represents the localization of schools, assessed following the same process as for the urban area.

corresponding to a random selection of different values of the calculation steps, thereby better spreading hazard and vulnerability uncertainties.

The median probability of exceeding damage level D2 (at least slight damage to the structure) is about $10^{-4}-10^{-3}$ per year and $10^{-2}-10^{-1}$ per $50 \mathrm{yr}$. Over $100 \mathrm{yr}$, the value reaches $10^{-2}$ to $10^{-1}$ in the most vulnerable areas (in the city centre). This reflects the lack of seismic resistance of the old masonry constructions in the city's historic quarters. The probabilities of building collapse per year, per $50 \mathrm{yr}$ and per $100 \mathrm{yr}$ are $10^{-6}-10^{-5}, 10^{-4}-10^{-3}$ and $10^{-2}-10^{-3}$, respectively. Certain variations within the city are apparent, thus distinguishing what appear to be the most vulnerable areas or the areas with major site effects. This also shows that the risk of collapse over $50 \mathrm{yr}$ (D5) is lower than the risk of seeing at least slight damage (D2). In a moderate seismic context, this observation is of interest since it enables the importance of seismic risk to be put into perspective, even if slight damage may still have direct economic consequences (need to reinforce or renovate).

In the figures, the triangles show the locations of the city's schools, whose vulnerability was evaluated in the Sismo-DT project using the same VULNERALP method as for other buildings (Gueguen et al., 2007b, 2009). Although this basic

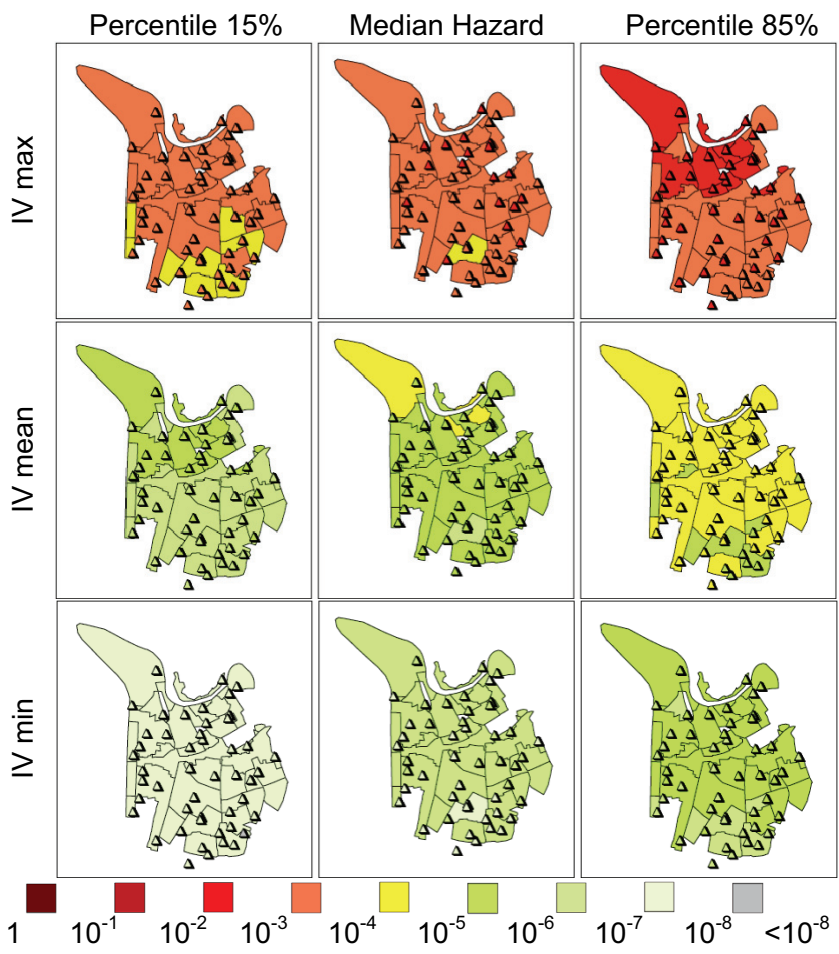

Fig. 12. Same as Fig. 11, damage D5.

empirical method cannot be considered significant for a single building, it does enable a hierarchy to be established for a group of buildings (in this case, schools), identifying the schools with the worst characteristics in terms of earthquake resistance. Extensive homogeneity is observed in the median probabilities of D2 and D5 between the schools and the areas, regardless of the return periods considered. This observation reflects the consequence of the city's urbanization over the ages, since urbanization has been accompanied by an increase in population, requiring the simultaneous construction of the school buildings required by the city authorities (Gueguen et al., 2009). The schools therefore have the same construction characteristics and the same vulnerability as the areas in which they are built.

In order to place the seismic risk assessed in the Grenoble urban area within a local context, the mortality rates associated with other types of risk were analyzed and compared with those of the seismic risk. The 2008 INSEE census in France enables evaluation of the mortality rate per age range. For an annual rate of $8.10^{-3}$, this rate obviously varies according to the age of the person: from $4.10^{-4}$ for under $20 \mathrm{~s}$ to $4.10^{-2}$ for over $65 \mathrm{~s}$. This risk can be considered as being natural, since it is unavoidable. The Emergency Events Database (EM-DAT) maintained by the Collaborating Centre for Research on the Epidemiology of Disasters, (Cred, 2003) gathers information on natural and technological disasters throughout the world. An analysis within mainland France enables extraction of the events occurring during the period 1900-2010 (Table 3). Based on the theory of an average 


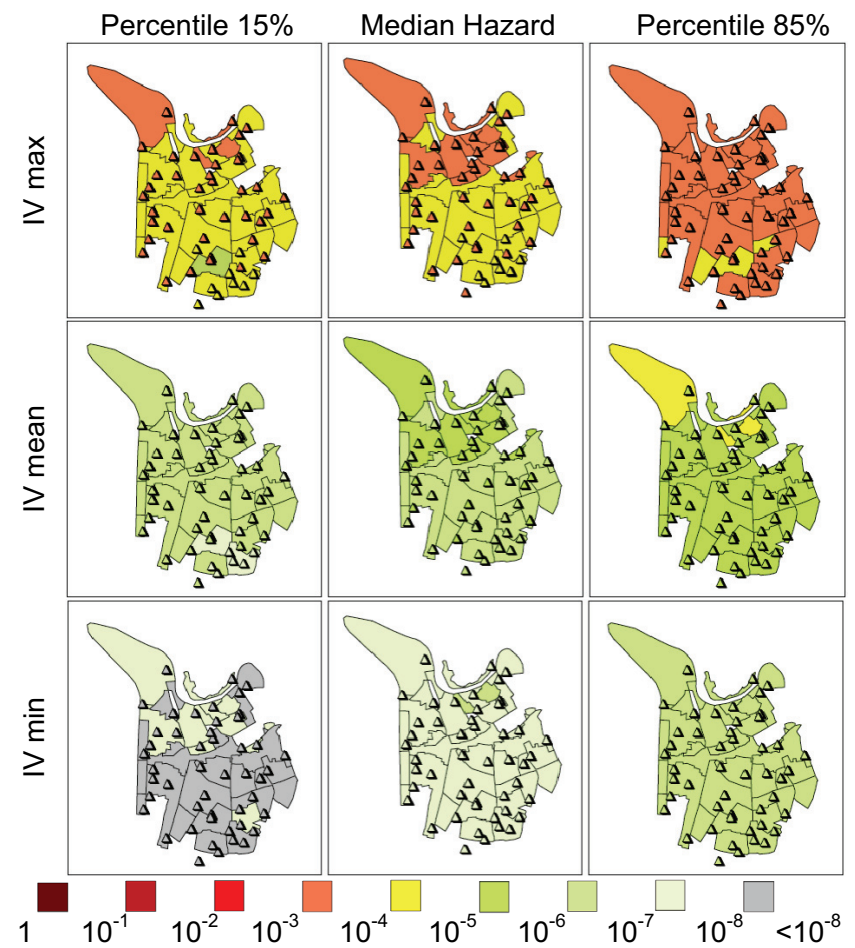

Fig. 13. Same as Fig. 11, individual casualty.

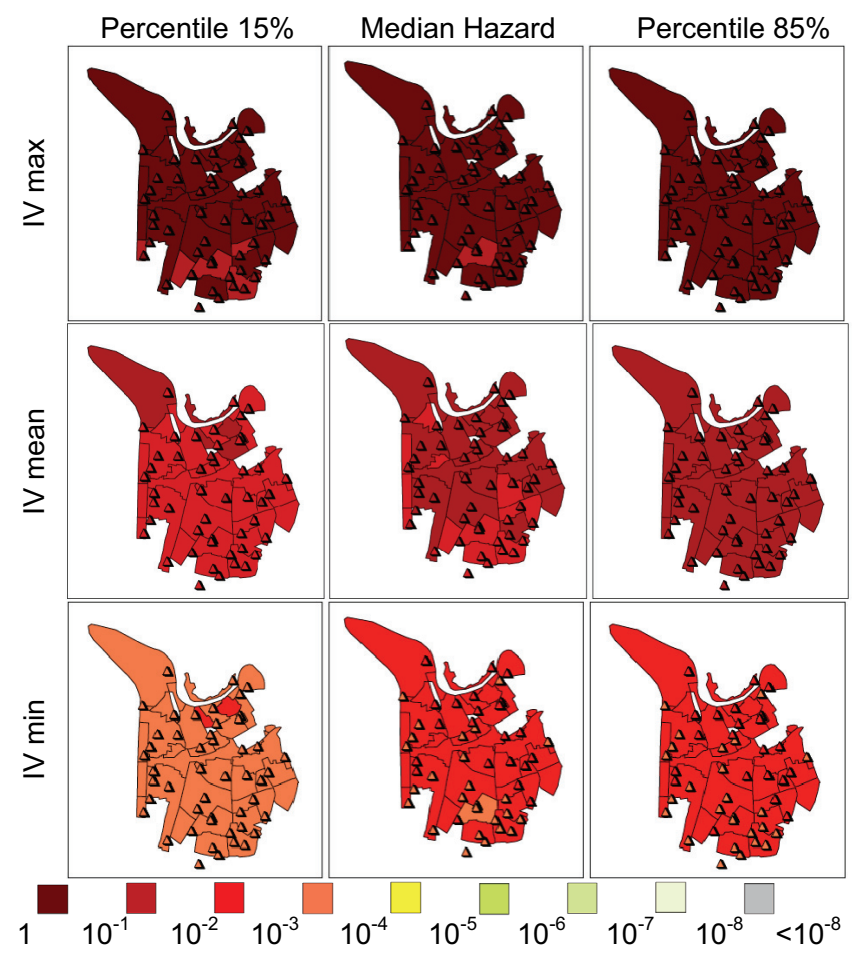

Fig. 14. Same as Fig. 11, damage D2, 50 yr probability.

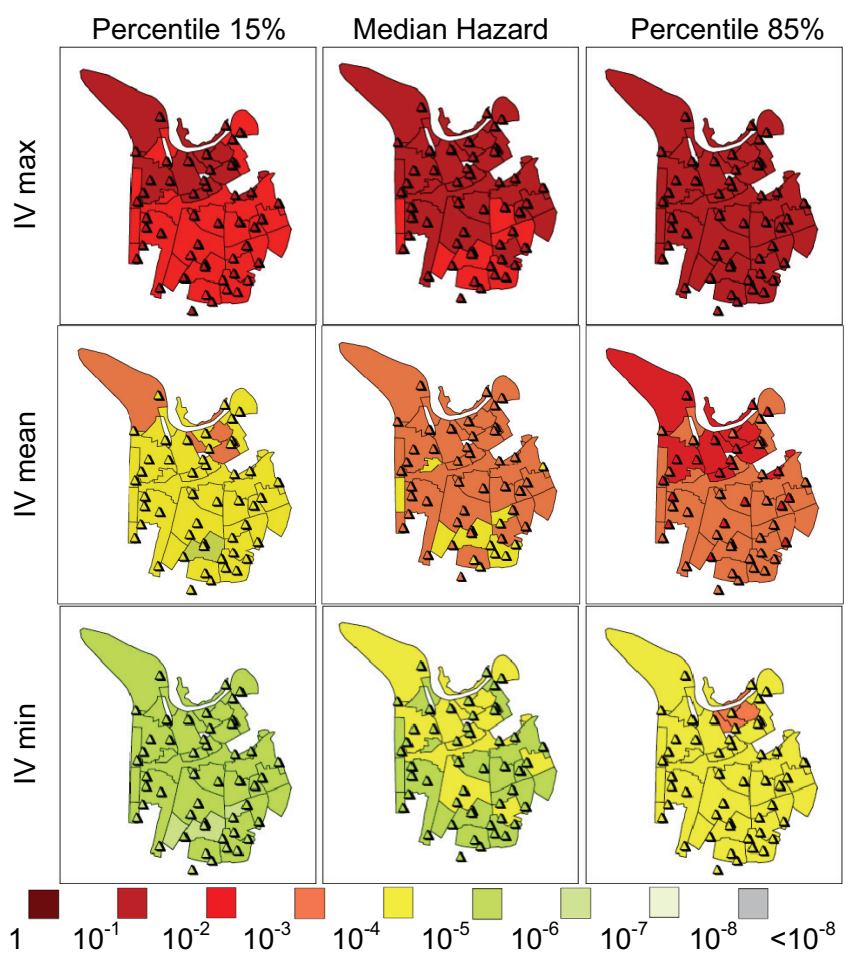

Fig. 15. Same as Fig. 11, damage D5, 50 yr probability.

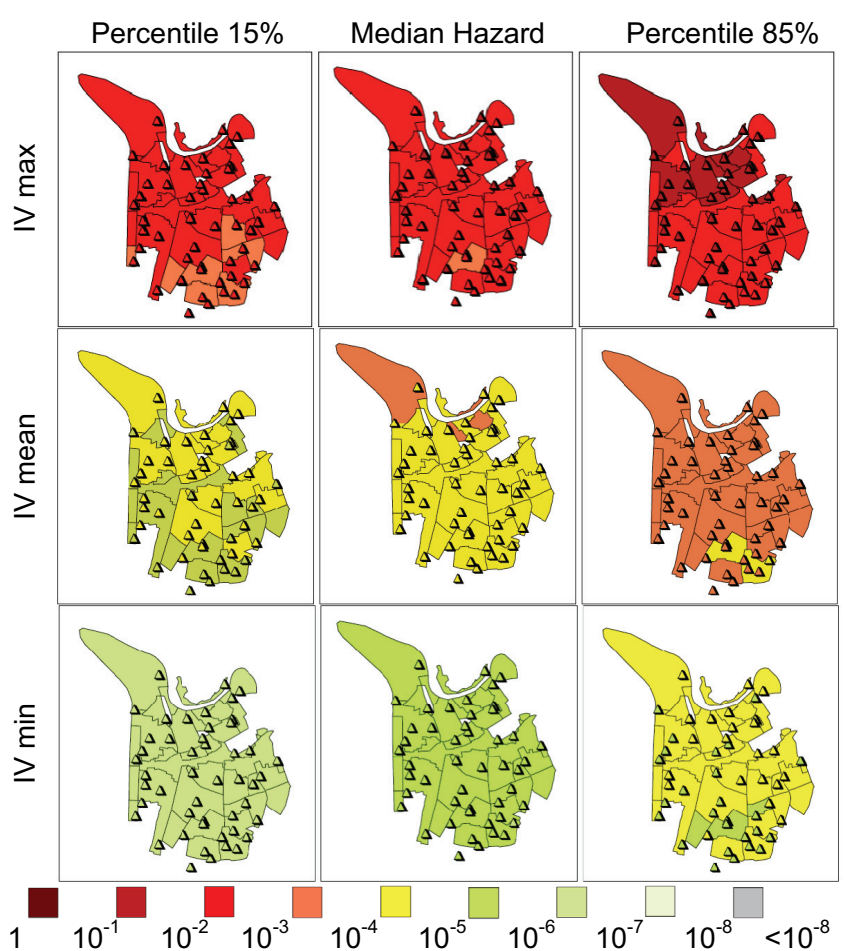

Fig. 16. Same as Fig. 11, individual casualty, 50 yr probability. 
Table 3. Annual rate of mortality (Rate) for different hazards (industrial, domestic and natural) corresponding to the number of events and associated casualties over the 1900-2010 period and corresponding to an average population of 50000000 inhabitants for France. Data have been provided by the EM-DATE: Emergency Events Database managed by the Collaborating Centre for Research on the Epidemiology of Disasters (Cred, 2003).

\begin{tabular}{lrrr}
\hline Events & Number & Casualties & Rate \\
\hline Extreme temperature & 12 & 20941 & $3.8 \times 10^{-6}$ \\
Traffic accidents & 49 & 3499 & $6.4 \times 10^{-7}$ \\
Other Accidents & 22 & 1502 & $2.7 \times 10^{-7}$ \\
Industrial accidents & 14 & 1221 & $2.2 \times 10^{-7}$ \\
Storms & 49 & 418 & $7.6 \times 10^{-8}$ \\
Floods & 38 & 225 & $4.1 \times 10^{-8}$ \\
Wet Landslide & 6 & 114 & $2.1 \times 10^{-8}$ \\
Forest fires & 12 & 112 & $2.0 \times 10^{-8}$ \\
Dry Landslide & 3 & 64 & $1.2 \times 10^{-8}$ \\
Earthquakes + tsunami & 2 & 57 & $1.0 \times 10^{-8}$ \\
Epidemic & 2 & 21 & $3.8 \times 10^{-9}$ \\
\hline
\end{tabular}

population of around 50 million during the last century, the greatest average annual mortality rates deduced is given for extreme temperature, that means all values are less than $3.810^{-6}$ considering all hazards.

Seismic activity in mainland France over the previous century shows a mortality rate of $1.0 \times 10^{-8}$. The national value should be taken with some precaution since a return period of a century is not enough to qualify destructive phenomena with long return periods. Furthermore, this is an average value for the whole territory, which has a highly variable seismic random event. In Grenoble, the average rate of mortality found in this study is between $10^{-5}-10^{-7}$, depending on the quarters (Fig. 13). According to the Ministry of Ecology and Transportation, 4443 people died on the roads in 2008 for a population of 64321374 on 1 January 2009. There are numerous analyses possible on this risk, according to age range, time spent on the road etc. but these figures show an average annual mortality rate of around $7.10^{-5}$ in France, which is similar to the average earthquake values in Grenoble. The road risk has increased with the traffic in the last two decades, given a higher rate than for the last century. The road risk is an example of an individual risk which is accepted by the population as a whole, in the sense that knowledge of the risk does not prevent individuals from using the road. However, the perception of this risk is sufficiently high for the public authorities to take action to reduce it and to commit to a wide range of decrees and laws concerning prevention, control and repression to reduce (or at least contain) this mortality risk.

In terms of the individual mortality risk due to an earthquake in Grenoble, this study does not intend to be alarmist, nor to encourage unnecessary melodrama. It has been conducted to enable representation of the risk run by an inhabitant of Grenoble in relation to the risks to which he/she is exposed on a daily or occasional basis. For example, the annual individual probability of dying because of the total collapse of a building during an earthquake is around $10^{-7}-10^{-6}$ (median value) in the peripheral suburbs of Grenoble and $10^{-6}-10^{-5}$ in the city's historic quarters. This rate is low because the annual probability of D5 damage is low. The annual mortality rate must be compared with the average annual probability of a 40 -yr old person in France dying for any reason whatsoever $\left(10^{-3}\right)$. This rate does not take into account certain situations, such as smoker or non smoker, genetic pre-dispositions, etc. However, a difference of 3 orders of magnitude can be observed, showing that the earthquake risk is not a risk that affects the all cause mortality rate. Inversely, annual mortality in 2008 due to a car accident in France shows a rate of $7 \cdot 10^{-5}$ which is close to the $10^{-6}-10^{-5}$ rate observed for an earthquake in the centre of Grenoble. This result must be considered cautiously since the traffic accidents rate is a national rate while the earthquake casualties' rate is regional. The seismic risk thus reaches the same level as that taken by car drivers, a level that is not enough to stop them from driving their cars. Although considered tolerable, since it is accepted, major political actions have been undertaken to reduce this risk. These measures concern prevention and education, repression and improving infrastructures. These measures can be compared with earthquake risk reduction actions, ranging from the information available to the population to the action to be taken during an earthquake, training for builders, adoption of adequate regulations and control of compliance with such regulations. In comparison with other similar natural and industrial risk phenomena, it appears that the mortality rate of an earthquake in Grenoble is the same as that of extreme temperatures $\left(10^{-6}\right)$, transport or industrial accidents $10^{-7}$ (Table 3) in France. However, it remains higher than other natural disasters $\left(10^{-8}\right)$ including floods, storms or landslides, which places earthquakes among the most important natural phenomena against which protection must be provided in France. Again, in Grenoble, exposed to natural hazards such as floods and rock falls, regional estimates should be considered for a whole and complete analysis of the Grenoble city risk. Moreover, global climate changes mean that these figures require review. In addition, over a period of $50 \mathrm{yr}$, the individual mortality rate is $10^{-4}-10^{-5}$. At $100 \mathrm{yr}$ (Supplement), i.e. the upper boundary of the lifetime for one generation, the individual mortality rate is $10^{-5}-10^{-4}$ in the city centre, peaking at $10^{-4}-10^{-3}$ in certain areas, i.e. a higher risk. These rates reflect the poor quality of the existing buildings.

\section{Conclusions}

Seismic studies based on hazard and vulnerability are becoming increasingly insufficient for the public authorities, 
which also require an evaluation of seismic risk. It is therefore necessary to find a coherent approach, between the regional hazard assessment, consideration of site effects, structural characteristics and the representation of consequences on the populations. This study, albeit incomplete, enables the identification of certain imperfections and certain steps that must be improved. Firstly, the study of regional hazard, integrating the progress made since the start of seismic zoning review in France, is probably the most advanced. However, the link between intensity and ground motion is not yet fully controlled and mastered, although a number of initiatives are underway in this field. This link must be completed with the consideration of site effects, which could be significantly improved if the hazard were defined in spectral parameters and not in intensity. If this were so, the difficulty would become the ground motion/damage prediction step, since most of the methods suitable for the city scale express probability of damage for a macroseismic intensity. We are therefore faced with two choices: to improve the intensity methods or to propose spectral parameter studies. This second solution was envisaged, integrating physical parameters in the estimation of structural vulnerability (Michel et al., 2010) but much remains to be done before a reproducible, standard method becomes available. However, using physical rather than empirical evaluation, the uncertainties related to the definition of a behavior model for each class of construction (Spence et al., 2003) will be reduced, a link will be forged between regional hazard and site effects and national regulatory zonings will result, all of which will enable a homogeneous approach to be proposed throughout the entire process.

In the case of Grenoble, it is clear that seismic risk is moderate in terms of the annual probability of damage, collapse, and loss. These results are obviously not complete: the notion of collective death risk must be introduced to represent the collective nature of loss during an earthquake (one building may collapse on several inhabitants), whereas the roadrelated risk is an individual risk. It is also necessary to consider the mobility of people during the course of the day, particularly for the schools concerned in this study, since occupancy varies over the week: the risk is therefore different during the day, on a week day or at the weekend. This first step will enable the authorities to take the necessary measures regarding existing buildings according to strategic choices that are economically viable. The notion of acceptable risk is introduced and economic considerations must be added to this study. Indeed, depending on the economic value of the building and the city's maintenance and investment policy for its buildings (Boudis et al., 2010), the risk will be higher or lower and therefore more or less acceptable. This approach could possibly enable the proposal of seismic risk evolution simulations for local authorities or building owners, depending on the actions they decide to implement.

\section{Supplementary material related to this article is available online at: http://www.nat-hazards-earth-syst-sci.net/12/511/2012/ nhess-12-511-2012-supplement.pdf.}

Acknowledgements. This work has been supported by the Isère regional Council, through the Pole Alpin des Risques Naturels program. This work benefited from the financial support of the DREAL (Direction Régionale de l'Environnement, de l'Aménagement et du Logement) and the FEDER in the framework of the RiskNat project in the ALCOTRA (2007-2013) programme.

Edited by: M. E. Contadakis

Reviewed by: P. Lestuzzi and another anonymous referee

\section{References}

Anderson, J. G., Bodin, P., Brune, J. N., Prince, J., Singh, S. K., Quaas, R., Onate, M.: Strong ground motion from the Michoacan, Mexico, earthquake, Science, 233, 1043-1049, 1986.

Arracoucau, P., Mocquet, A., and Vacher, P.: Atténuation de l'intensité macrosismique pour la France métropolitaine: importance de l'intensité épicentrale, C. R. Geoscience, 338, 596-605, 2006.

Astorza, M. and Monje, J.: Regional seismic zonation in Central Chile, Proc. 4th Int. Conf. Seismic Zonation, EERI editor, 25-29 August, Stanford, california, 487-494, 1991.

ATC 21: Rapid visual screening of buildings for potential seismic hazards: a handbook, Applied Technology Council, Redwood City, California, 1988.

Augenti, N., Cosenza, E., Dolce, M., Manfredi, G., Masi, A. and Samela, L.: Performance of school buildings during the 2002 Molise, Italy, earthquake, Earthquake Spectra, 20, 257-270, 2004.

Baize, S., Cushing, M., Lemeille, F., Granier, T., Grellet, B., Carbon, D., Combes, Ph., and Hibsch C.: Inventaire des indices de rupture affectant le quaternaire, en relation avec les grandes structures connues en France métropolitaine et dans les régions limitrophes, IRSN, Mémoires de la société géologique de France, 175, 142 pp., 2002.

Beauval, C., Bard, P.-Y., Hainzl, S., and Guguen, P.: Can Strong-Motion Observations be Used to Constrain Probabilistic Seismic-Hazard Estimates, Bull. Seismol. Soc. Am., 98, 509520, doi:10.1785/0120070006, 2008.

Benedetti, D. and Petrini, V.: On seismic vulnerability of masonry buildings: proposal of an evaluation procedure, Industria delle Costruzioni, 18, 66-78, 1984.

Bommer, J. J., Scherbaum, F., Bungum, H., Cotton, F., Sabetta, F., and Abrahamson, N. A.: On the use of logic trees for ground-motion prediction equations in seismic-hazard analysis, Bull. Seismol. Soc. Am., 95, 377-389, doi:10.1785/0120040073, 2005.

Borcherdt, R. D. and Gibbs, J. F.: Effects of local geological conditions in the San Francisco Bay region on ground motions and the intensities of the 1906 earthquake, Bull. Seismol. Soc. Am., 66, 467-500, 1976.

Boudis, M., Saillard, Y., Guguen, P., and Davoine, P.-A.: Modèle d'aide à la décision pour la prévention parasismique urbaine: 
une approche multi-agents de la vulnérabilité du bâti, European Journal of GIS and Spatial Analysis, 20, 279-302, doi:10.3166/rig.20.279-302, 2010.

Breysse, D.: Maîtrise des risques en Génie Civil: Volume III, Sécurité des constructions et réglementation, Hermès-Lavoisier, Paris, 270 pp., ISBN2-7462-2443-7, 2009.

Coburn, A. and Spence, R.: Earthquake Protection, Edn. John Wiley \& Sons, 420 pp., 2002.

Collaborating Centre for Research on the Epidemiology of Disasters: Emergency Events Database - EM-DAT, available at: http://www.em-dat.net, 2003.

Combescure, D., Gueguen, P., and Lebrun, B.: Vulnérabilité sismique du bâti existant: approche d'ensemble, Cahier technique, AFPS, 25, 121 pp., 2005.

Cornou, C., Bard, P.-Y., and Dietrich, M.: Contribution of dense array analysis to the identification and quantification of basin-edge induced waves, Part II: Application to Grenoble basin (French Alps), Bull. Seismol. Soc. Am., 93, 624-648, 2003.

Dolce, M., Masi, A., Marino, M., and Vona, M.: Earthquake damage scenarios of the building stock of Potenza (Southern Italy) including site effects, Bull. Earthquake. Eng., 1, 115-140, 2003.

Ergunay, O. and Gulkan, P.: Seismic risk reduction and disaster management: national report of Turkey, in: Proceedings of workshop on seismic risk reduction and disaster management, Roma, Italy, November, 1991.

Faccioli, E., Pessina, V., Calvi, G. M., and Borzi, B.: A study on damage scenarios for residential buildings in Catania City, J. Seismol., 3, 327-343, 1999.

Farsi, M. and Bard, P.-Y.: Estimation des périodes propres de bâtiments et vulnérabilité du bâti existant dans l'agglomération de Grenoble, Revue française de génie civil, 8, 149-179, 2004.

FEMA 178: NEHRP handbook for the seismic evaluation of existing buildings. Federal Emergency Management Agency, 1997.

GNDT: Rischio sismico di edifici pubblici Parte I: aspetti metodologici, Centro Servizi Quasco, Bologna, 1993.

Grellet, B., Combes, P., Granier, T., and Philip, H.: Sismotectonique de la France métropolitaine dans son cadre géologique et géophysique avec atlas de 23 cartes au 1/4 000 000ème et 1 carte au 1/1 000 000ème. Mémoire Société Géologique de France, no 164, 1, 76 pp., 1993.

Grunthal, G. and Levret, A.: L'échelle macrosismique européenne, Conseil de l'Europe - Cahiers du Centre Européen de Géodynamique et de Séismologie, 19, 2001.

Gueguen, P., Chatelain, J.-L., Guillier, B., Yepes, H., and Egred, J.: Site effect and damage distribution in Pujili (Ecuador) after the 28 March 1996 earthquake, Soil Dynam. Earthq. Eng., 17, 329-334, 1998.

Gueguen, P., Chatelain, J.-L., Guillier, B., and Yepes, H.: An indication of the soil topmost layer response in Quito (Ecuador) using H/V spectral ratio, Soil Dynam. Earthq. Eng., 19, 127-133, 2000.

Gueguen, P., Michel, C., and Lecorre, L.: A simplified approach for vulnerability assessment in moderate-to-low seismic hazard regions: application to Grenoble (France), Bull Earthq. Engng., 4, 467-490, 2007.

Gueguen, P., Cornou, C., Garambois, S., and Banton, J.: On the limitation of the $\mathrm{H} / \mathrm{V}$ spectral ratio using seismic noise as an exploration tool: application to the grenoble valley, a small apex ratio basin, Pure Appl. Geophys., 164, 115-134, doi:10.1007/s00024- 006-0151-x, 2007.

Gueguen, P., Lutoff, C., Davoine, P. A., Taliercio, G., Cotton, F. and Cartier, S.: Analyse de la vulnérabilité sismique dans un pays à sismicité modérée: le cas de Grenoble, Risques naturels et environnement, edited by: Becerra, S. and Peltier, A., Risques et environnement: recherches interdisciplinaires sur la vulnérabilité des sociétés, Paris, L’Harmattan, 575 pp., 285-301, 2009.

Guyoton, F., Fréchet, J., and Thouvenot, F.: La crise sismique de janvier 1989 en Haute-Ubaye (Alpes-de-haute-Provence, France): étude fine de la sismicité par le nouveau réseau SISMALP, Comptes rendus de l'Académie des sciences, Série 2, Mécanique, Physique, Chimie, Sciences de l'univers, Sciences de la Terre, 311, 985-991, 1990.

HAZUS: Earthquake loss estimation methodology, Hazus technical manuals, National Institute of Building Science, Federal Emergency Management Agency (FEMA), Washington, 1997.

Jongmans, D. and Plumier, A.: Etude Pilote du risque sismique sur une partie de la ville de Liège, rapport interne, Université de Liège, Faculté des sciences appliquées 2000 (in French).

Lagomarsino, S. and Giovinazzi, S.: Macroseismic and mechanical models for the vulnerability and damage assessment of current buildings, Bull. Earthq. Eng., 4, 415-443, 2006.

Lebrun, B., Hatzfeld, D., and Bard, P.-Y.: A site effect study in urban area: experimental results in Grenoble (France), Pure Appl. Geophys., 158, 2543-2557, 2001.

Levret, A., Backe, J. C., and Cushing, M.: Atlas of macroseismic maps for French earthquakes with their princial characteristics, Nat. Hazards, 10, 19-46, 1994.

Levret, A. M., Cushing, M., and Peyridieu, G.: Recherche des caractéristiques des séismes en France. Atlas de 140 cartes macroseismiques, edited by: IPSN, Fontenay-aux-Roses, France, 2, 1996.

Martin, C., Combes, C., Secanell, R., Lignon, G., Carbon, D., Fioravanti, A., and Grellet, B.: Révision du zonage sismique de la France. Etude probabiliste, Rapport GEOTER GTR/MATE/0701-150, 417 pp., 2002.

Martin, C., Secanell, R., Viallet, E., and Humbert, N.: Consistency of PSHA Models in Acceleration and Intensity by Confrontation of Predictive Models to Available Observations in France, CSNI Workshop on "Recent Findings and Developments in PSHA Methodologies and Applications", Lyon Congress Centre. LyonFrance, 7-9 April 2008, 2008.

Medvedev, J.: Engineering Seismology, Academia Nauk Press, Moscow, 260 pp., 1962.

Medvedev, S. V., Sponheuer, W., and Karnik, V.: Seismic Intensity Scale MSK 1964, Akad. Nauk. SSSR, Geofiz. Kom., 257 pp., 1965.

Michel, C., Guéguen, P., Lestuzzi, P., and Bard, P.-Y.: Comparison between seismic vulnerability models and experimental dynamic properties of existing buildings in France, Bull. Earthq. Eng., 8, 1295-1307, doi:10.1007/s10518-010-9185-7, 2010.

Milutinovic, Z. and Trendafiloski, R.: An advanced approach to earthquake risk scenarios with applications to different European towns, Projet europen Risk-UE, 2003.

Musson, R. M. W., Grünthal, G., and Stucchi, M.: The comparison of macroseismic intensity scales, J. Seismol., 14, 413-428, 2010

Nicoud, G., Royer, G., Corbin, J.-C., Lemeille, F., and Paillet, A.: Glacial erosion and infilling of the Isre Valley during the recent Quaternary, Géologie de la France 4, 39-49, 2002. 
Oliveira, C. S.: Seismic vulnerability of historical constructions: a contribution, Bull Earthq. Eng., 1, 37-82, 2003.

Onur, T., Ventura, C. E., and Liam Finn, W. D.: Regional seismic risk in British Columbia damage and loss distribution in Victoria and Vancouver, Can. J. Civ. Eng., 32, 361-371, 2005.

Otani, S.: Seismic vulnerability assessment methods for buildings in Japan, Earthq. Eng. Eng. Seismol., 2, 47-56, 2000.

Parent, J.-F.: Grenoble, deux sicles d'urbanisme, Presse Universitaire de Grenoble, 187 pp., 1982.

Pequegnat, C., Gueguen, P., Hatzfeld, D., and Langlais, M.: The French Accelerometric Network (RAP) and National Data Centre (RAP-NDC), SRL, 79, 79-89, 2008.

RiskUE: An advanced approach to earthquake risk scenarios with applications to different european towns, Projet Européen, EVK4-CT-2000-00014, edited by: Roca, A., Goula, X., Susagna, T., Chávez, J., González, M., and Reinoso, E., A simplified method for vulerability assessment of dwelling buildings and estimation of the damage scenarios in Catalonia (Spain), Bull. Earthq.e Eng., 4, 141-158, 2003.

Seismocare: Seismocare Computed Aided Reduction of Seismic Risk with application to existing cities, town planning and construction - Directions to fill in the vulnerability form GNDT levels 1 and 2, European project Environment and Climate, 19941998, ENV4-CT970588, 1998.

Shima, E.: Seismic microzoning map of Tokyo, in Proc. 2nd Int. Conf. on Seismic Zonation, I, 519-530., 1978.
SIA 2018: Vérification de la sécurité parasismique des bâtiments existants, Société suisse des ingénieurs et des architectes, Zurich, 2004, 2004.

Spence, R. and Lebrun, B. (Eds.): Earthquake scenarios for European cities the risk-UE project, Bull. Earthqu. Eng., 4, special issue, 2006.

Spence, R., Bommer, J., Del Re, D., Bird, J., Aydinoglu, N., and Tabuchi, S.: Comparing loss estimation with observed damage: a study of the 1999 Kocaeli earthquake in Turkey, Bull. Earthq. Eng., 1, 83-113, 2003.

Steimen, S., Faeh, D., Giardini, D., Bertogg, M., and Tschudi, S.: Reliability of building inventories in seismic prone regions, Bull. Earthq. Eng., 2, 361-388, 2004.

Stepp, J. C.: Analysis of completeness of the earthquake sample in the Puget Sound area and its effect on statistical estimates of earthquake hazard, Proc. Microzonation Conf., Seattle, WA, 897-909, 1972.

Thouvenot, F., Fréchet, J., Jenatton, L., and Gamond, J.-F.: The Belledonne Border Fault: identification of an active seismic strike-slip fault in the Western Alps, Geophys. J. Int., 155, 174192, 2003.

Ventura, C. E., Liam Finn, W. D., Onur, T., Blanquera, A., and Rezai, M.: Regional seismic risk in British Columbia classification of buildings and development of damage probability functions, Can. J. Civ. Eng., 32, 372-387, 2005.

Weichert, D. H.: Estimation of the earthquake recurrence parameters for unequal observational periods for different magnitudes, Bull. Seismol. Soc. Am., 70, 1337-1346, 1980. 